\title{
Delivering complexity at the frontier of electronics
}

\section{Michael Mayberry}

Michael C. Mayberry, "Delivering complexity at the frontier of electronics," Proc. SPIE 8880, Photomask Technology 2013, 888002 (22 October 2013); doi: $10.1117 / 12.2032077$

SPIE Event: SPIE Photomask Technology, 2013, Monterey, California, United States 


\title{
Delivering Complexity at the
}

Frontier of Electronics

\author{
Mike Mayberry \\ Director of Components Research \\ VP, Intel Corporation
}

September 2013

(intel)

Photomask Technology 2013, edited by Thomas B. Faure, Paul W. Ackmann, Proc. of SPIE

Vol. 8880, 888002 - @ 2013 SPIE · CCC code: 0277-786X/13/\$18 - doi: 10.1117/12.2032077 


\section{Complexity Sells}

- Enables the impossible to become possible

- Complexity that enables simplicity of use

- Complexity can take many forms (density, structure, data, function, ...) but ultimately people pay for use

- Delivering complexity makes our business go! 


\section{You Are Here}

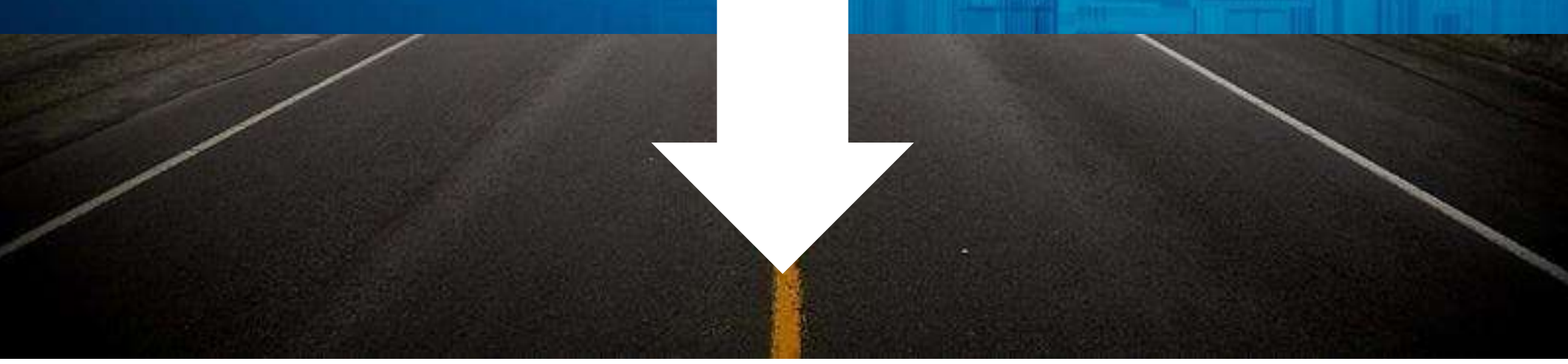

Proc. of SPIE Vol. $8880888002-3$

Downloaded From: https://www.spiedigitallibrary.org/conference-proceedings-of-spie on 26 Apr 2023 Terms of Use: https://www.spiedigitallibrary.org/terms-of-use 


\section{"Any sufficiently advanced technology is indistinguishable from magic" \\ - Arthur C. Clarke 1973}

\section{$1 \times 10^{9}$}

1 billion transistors fit into an area of One square centimeter

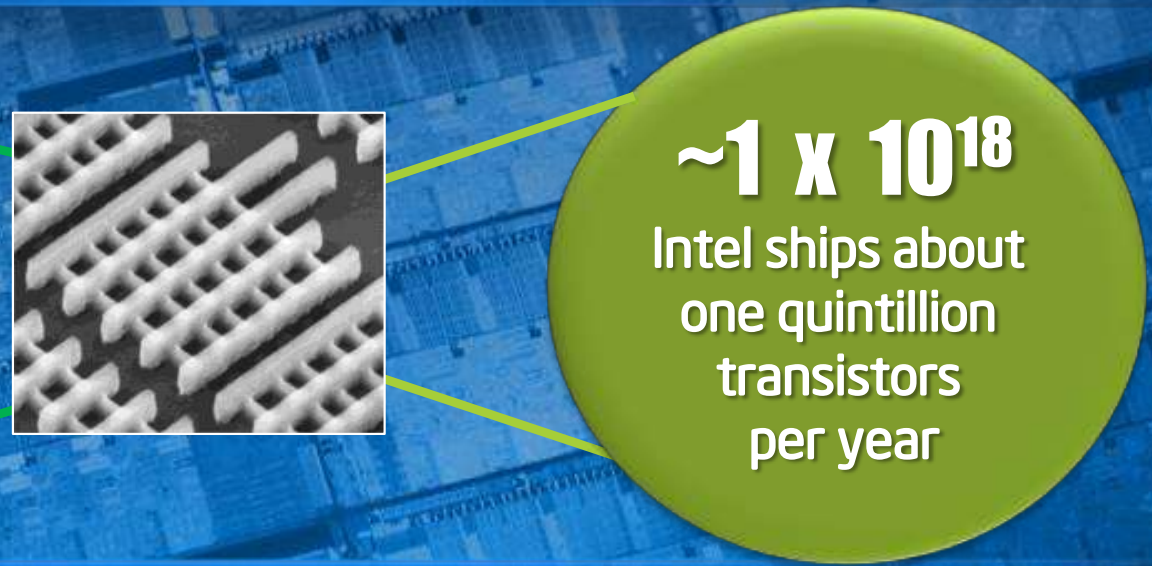

Intel 2013

\section{ENGII \\ 2yoars}

Intel delivers a new

manufacturing

process

\section{X \\ ietior}

than the previous

generation

\section{Intel in the Future}




\section{We Need Both New Materials \& New Structures}

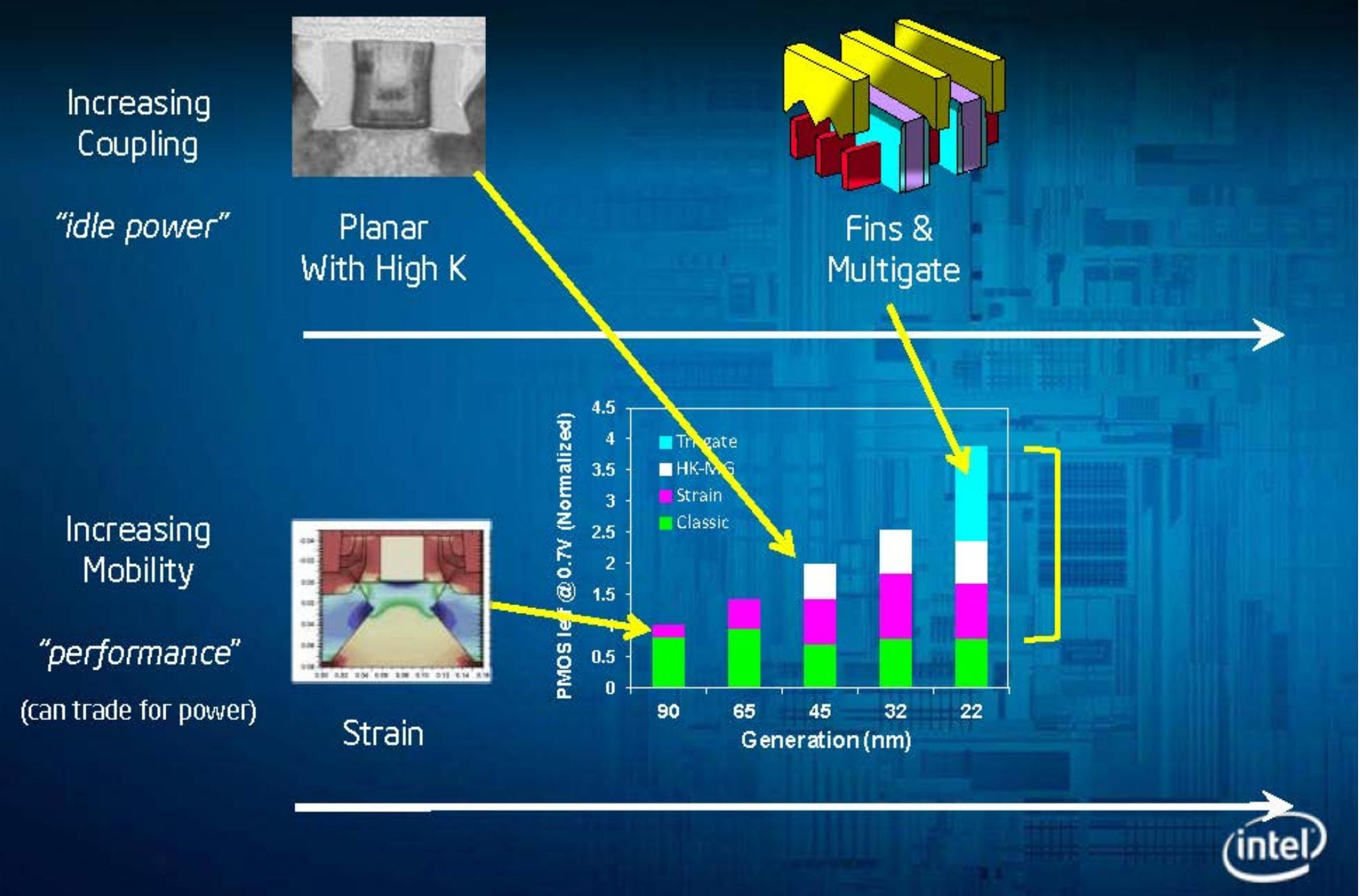



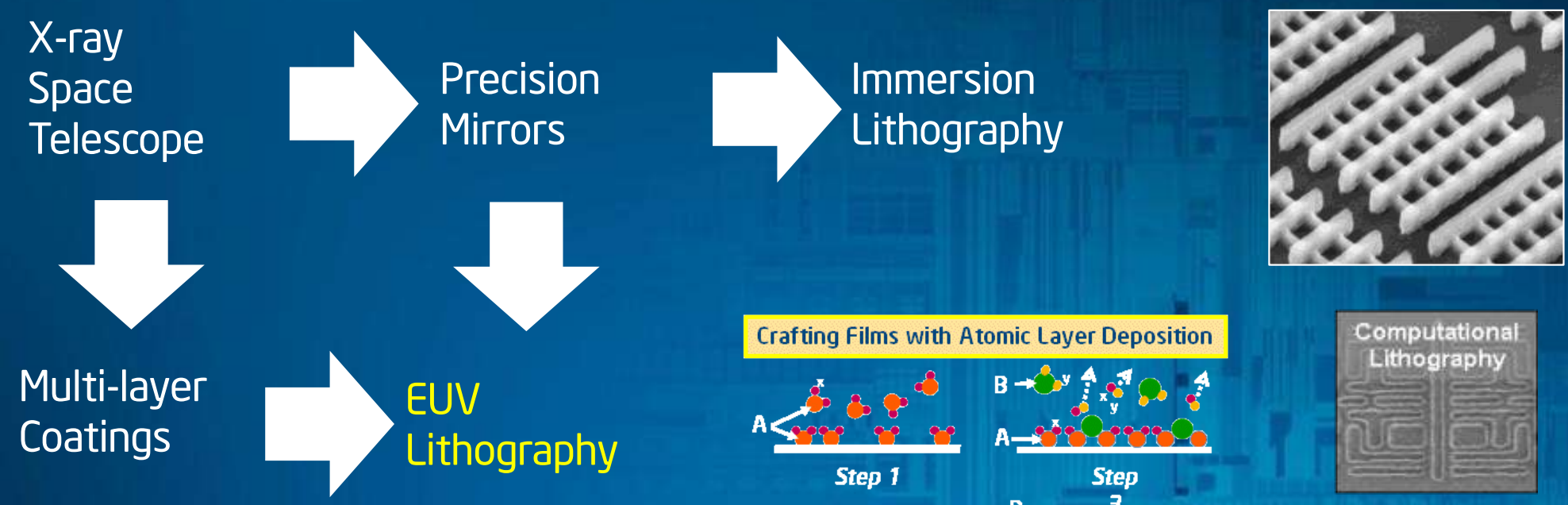

\section{Need Multiple Applied Sciences to reap benefits}
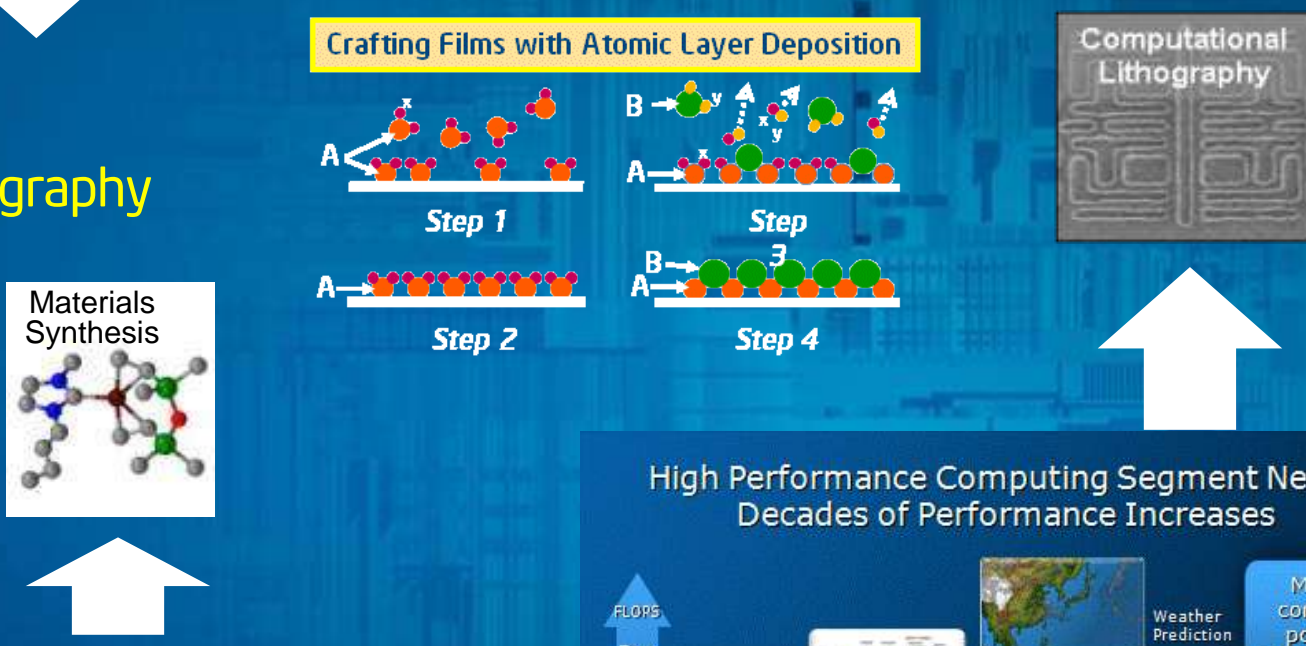

High Performance Computing Segment Needs Decades of Performance Increases

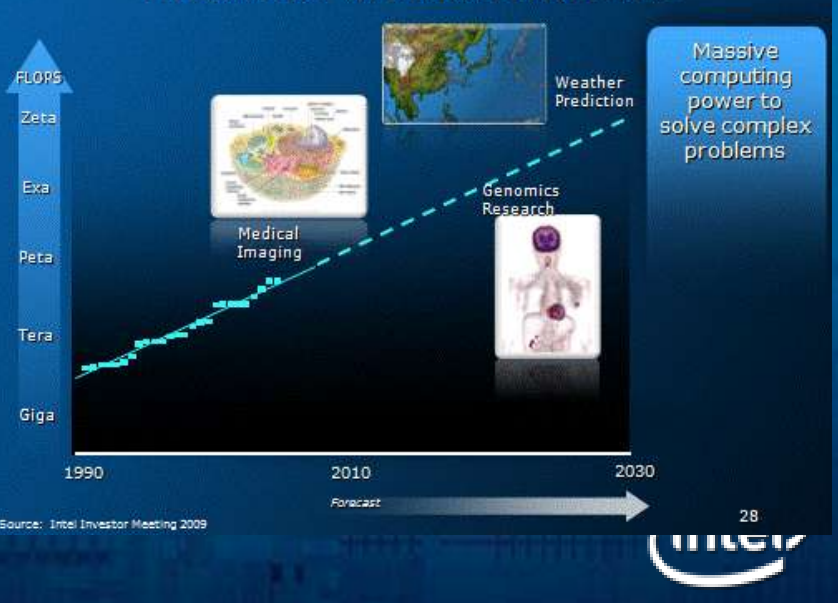


Level of detail

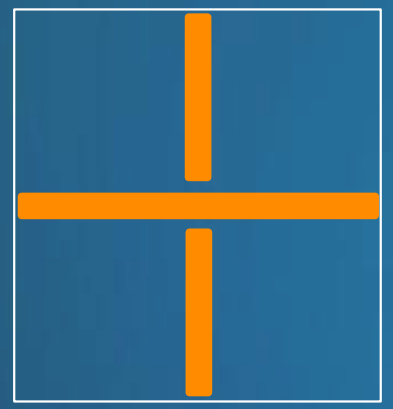

No OPC

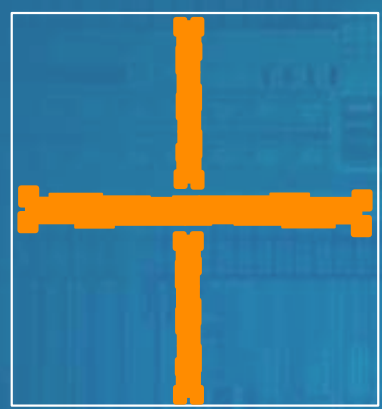

Model/Rule based OPC

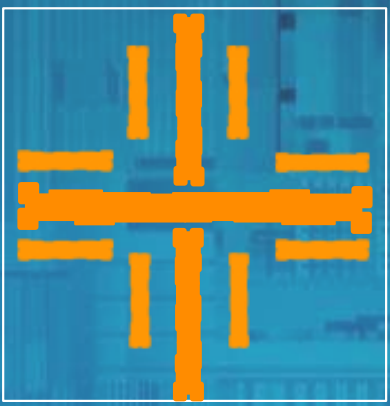

aggressive OPC + assist features

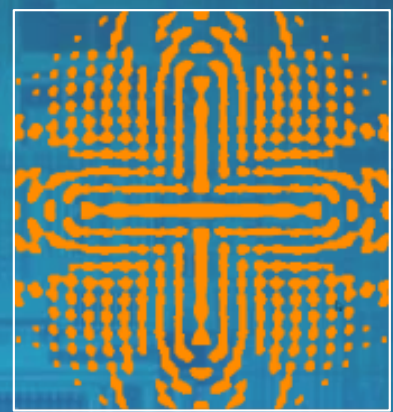

Inverse lithography

\section{1 billion transistors}

60 billion design features

\section{1 trillion mask features}




\section{The Evolution of PERSONAL COMPUTING}

\section{Productivity}

80 s and 90 s

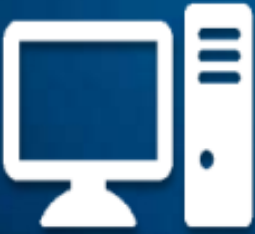

\section{Portability}

\section{$00 \mathrm{~s}$}

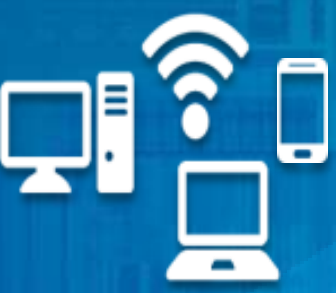

\section{Ubiquity}

$10 \mathrm{~s}$

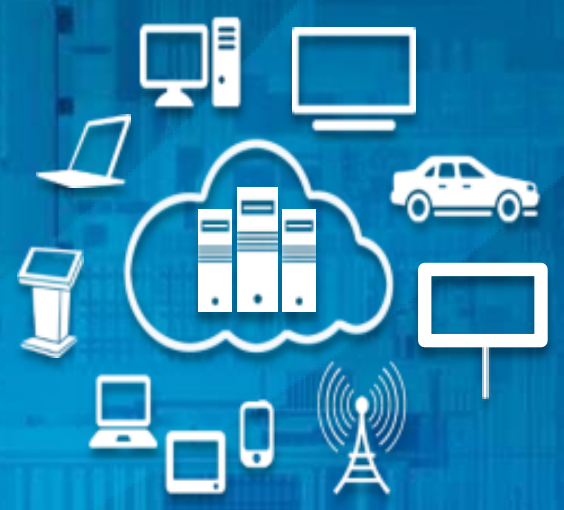




\section{What Happens in an Internet Minute?}
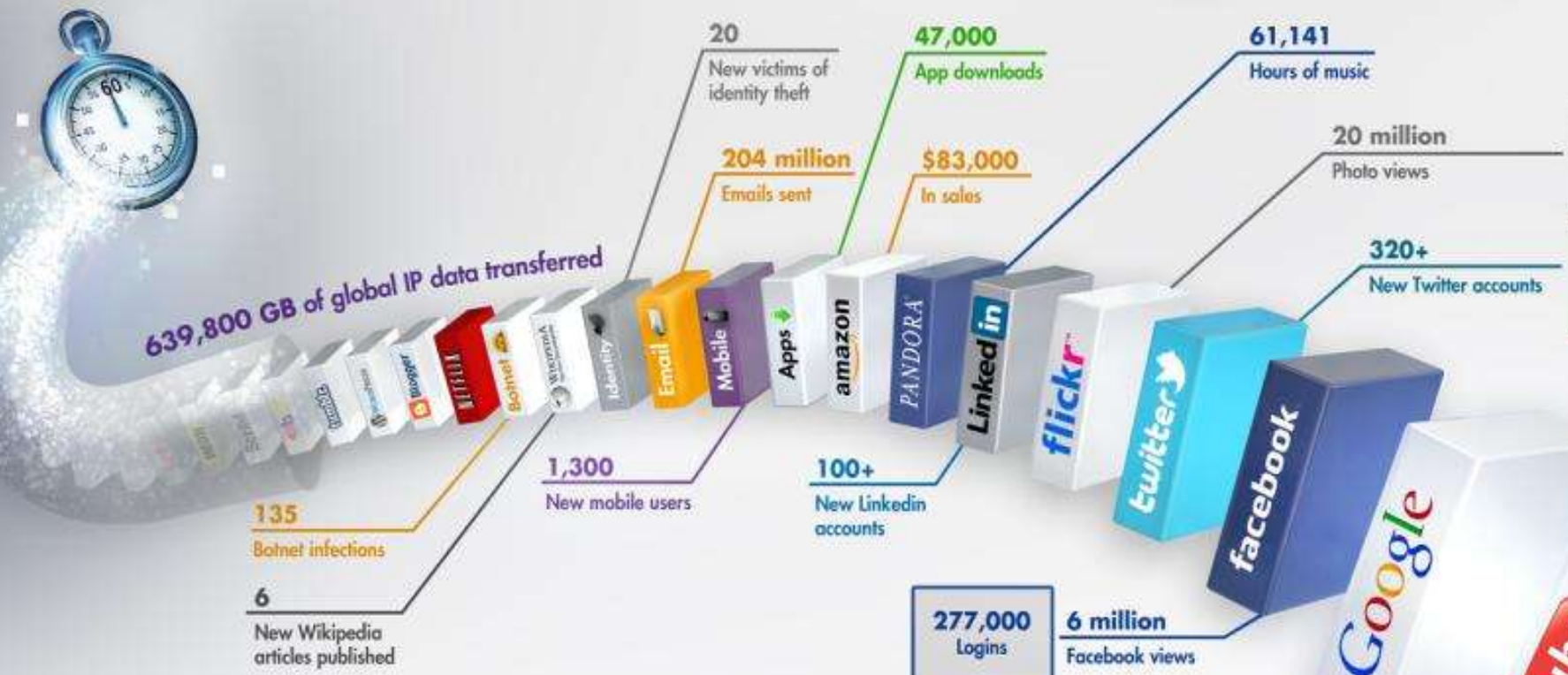

3,000 Photo uploods

100,000

New tweets
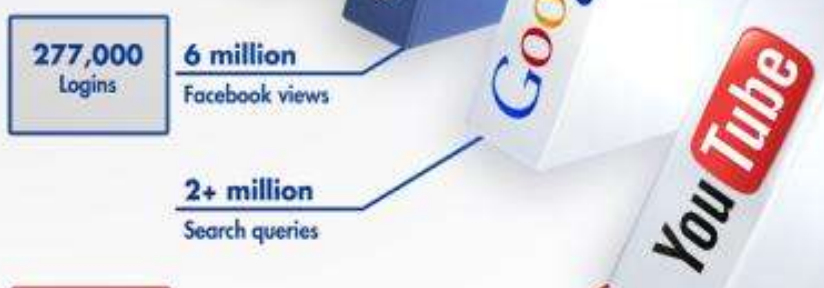

\section{And Future Growth is Staggering}
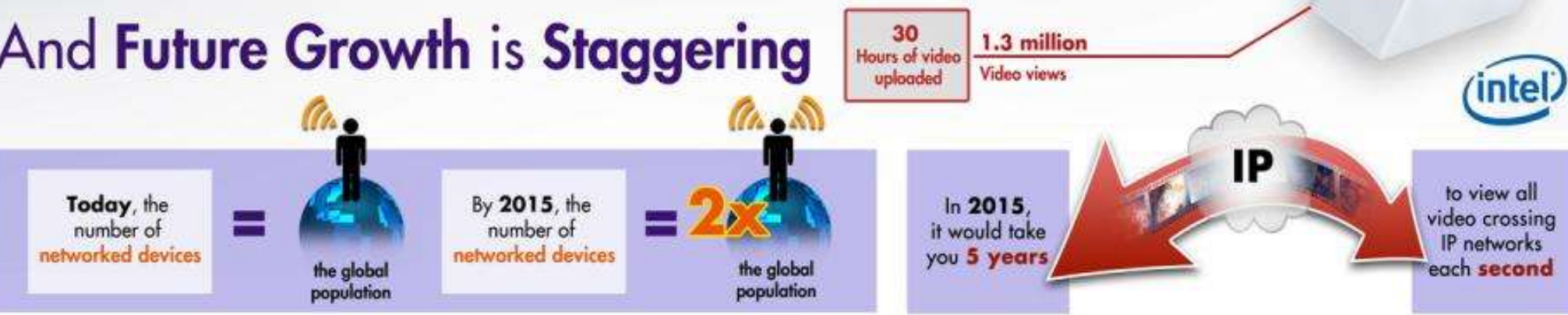

to view all video crossing IP networks each second 


\section{Key Points}

- Complexity just from density is insufficient and it has been that way for a decade or more ... increasing value from structure (materials), functions, and data

- Complexity that enables simplicity of use is driving the end market more today than in the past

- Delivering complexity at the right price point makes our business go ! 


\section{The (likely) near future}

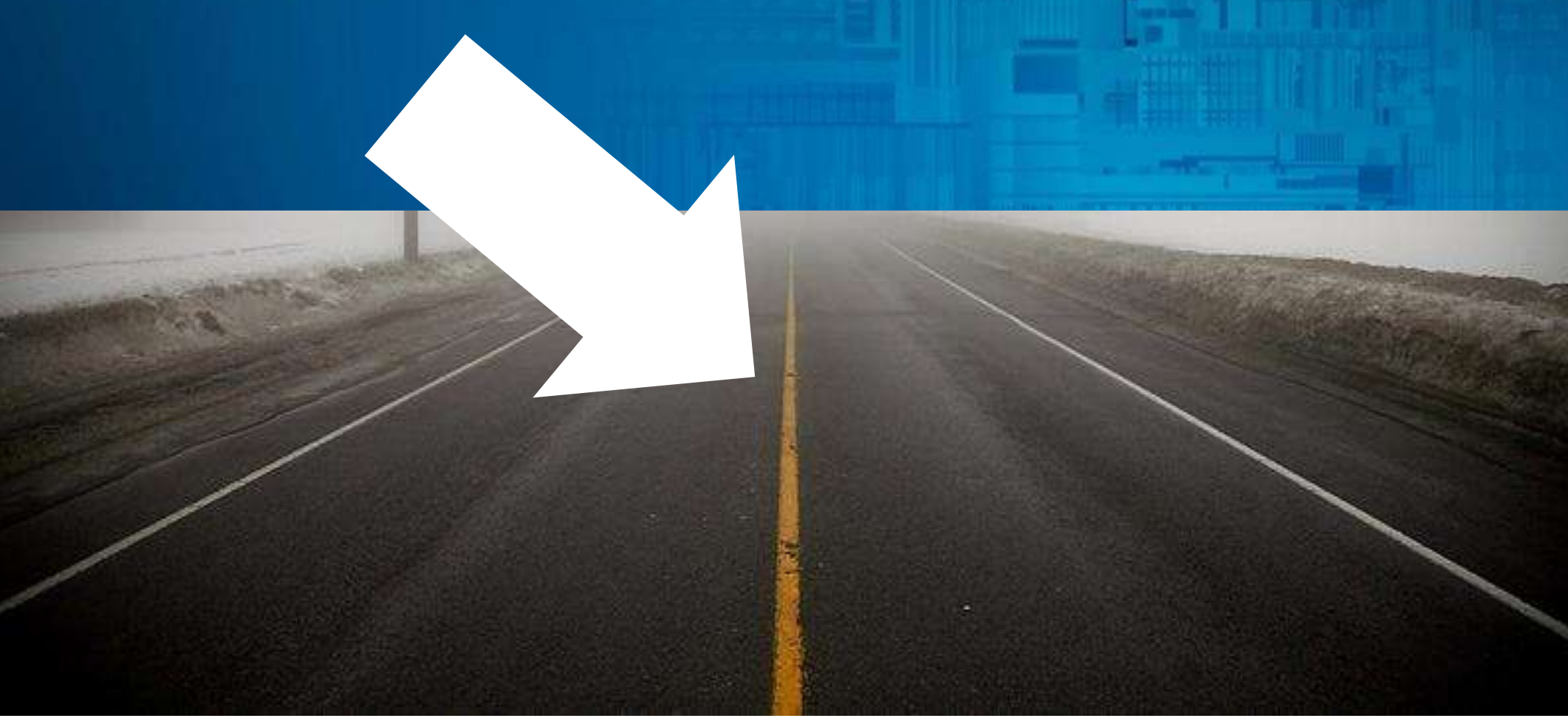

Proc. of SPIE Vol. $8880888002-11$

Downloaded From: https://www.spiedigitallibrary.org/conference-proceedings-of-spie on 26 Apr 2023 Terms of Use: https://www.spiedigitallibrary.org/terms-of-use 


\section{Optimizing Choices for Transistors on Multiple Fronts}

\author{
Increasing \\ COUPLING
}

(better OFF) With High K

Increasing MOBILITY

(better ON)

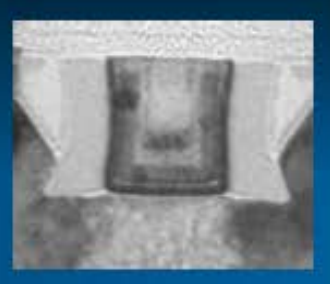

\section{Planar}

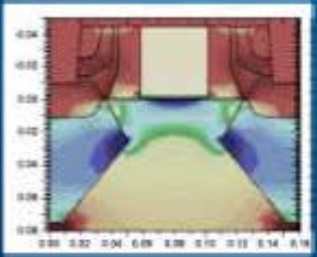

Strain

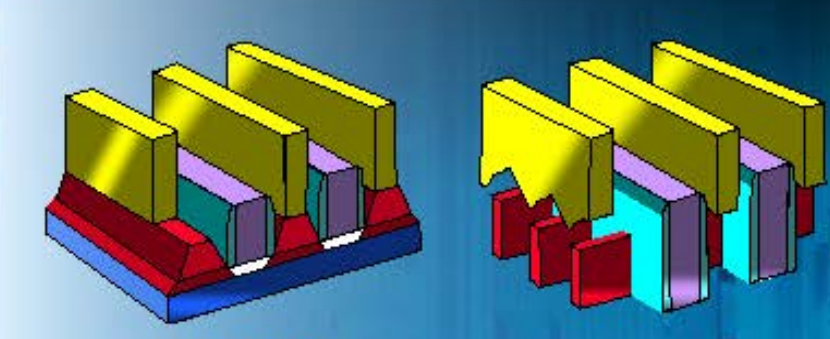

Fins

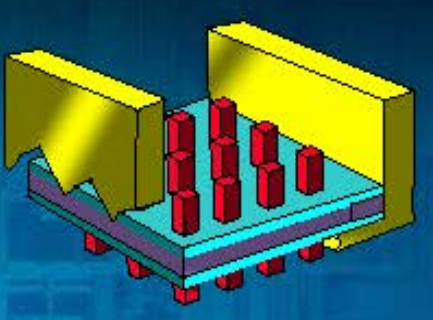

Wires/Dots

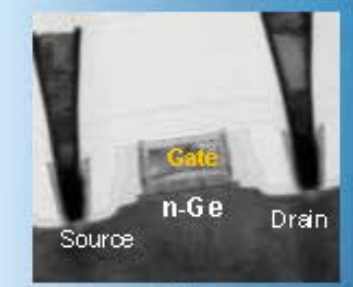

$\mathrm{Ge}$

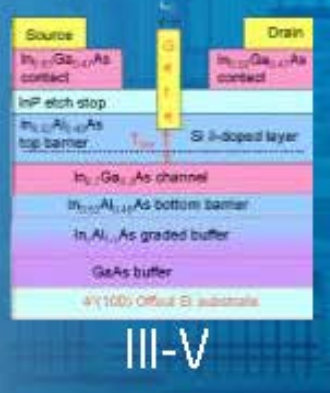

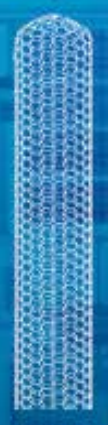

CNT

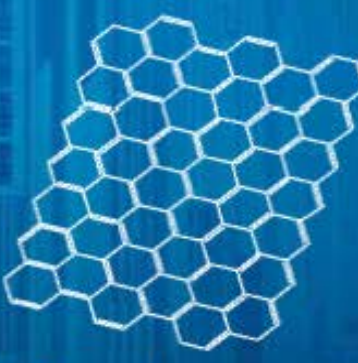

Graphene 


\section{Optimizing Choices for Printed Information}

Line Double (\& Quadruple)

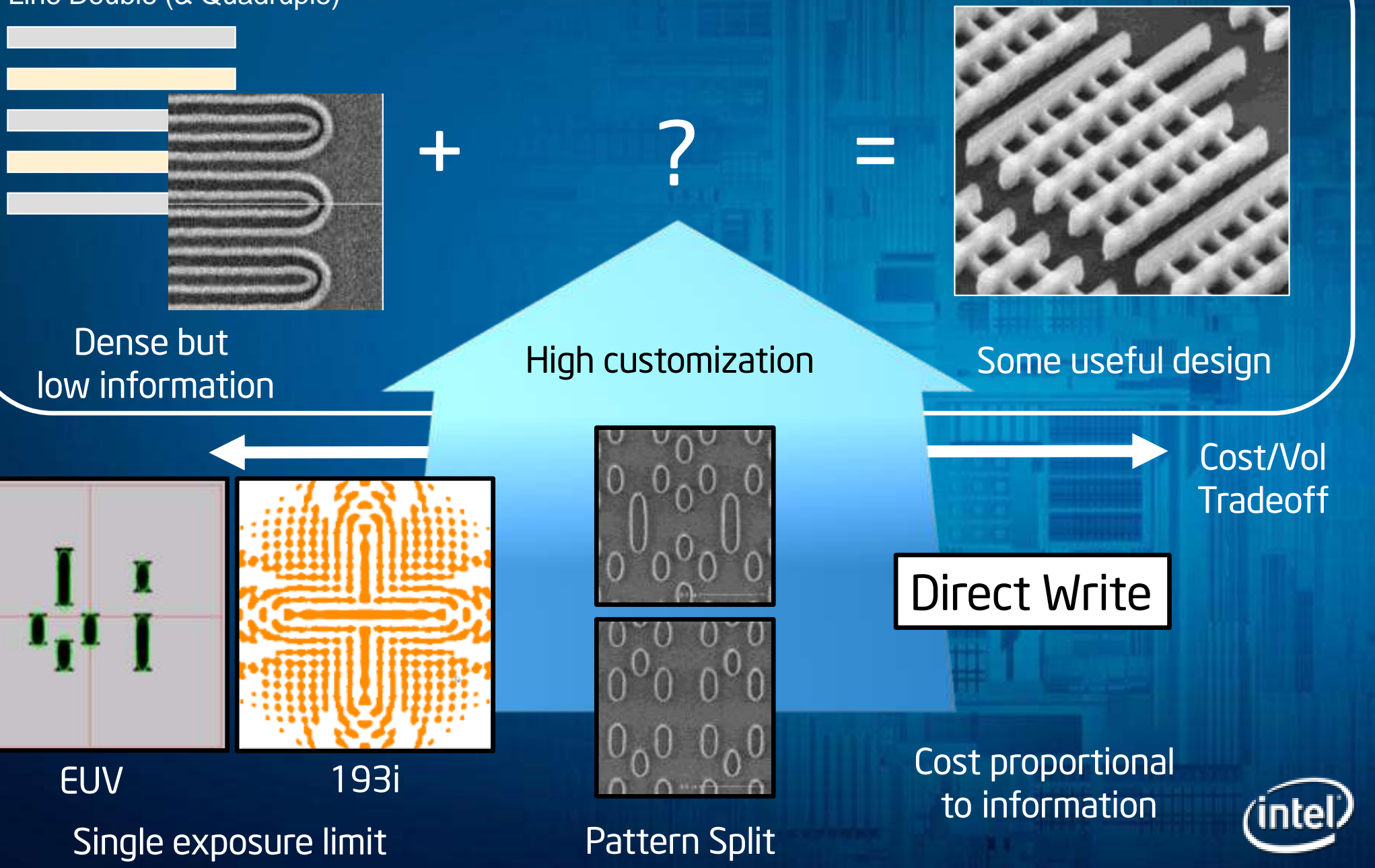




\section{The Gate All Around (GAA) Architecture is the Limit to Structural Electrostatic Control}
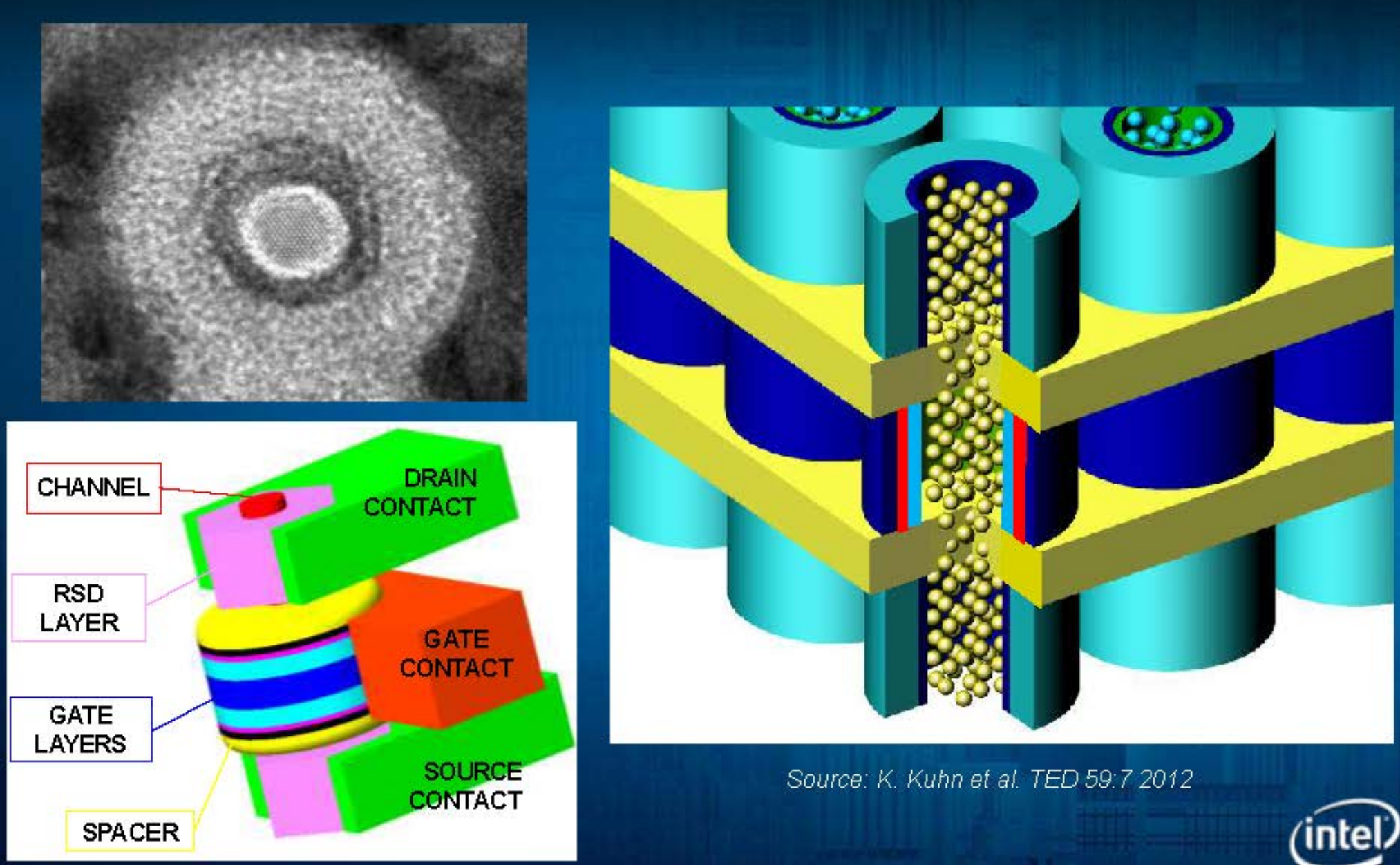

Source: K. Kuhn ef al. TED 59:7 2012 


\section{Increasing Capability (Information) of a Single Mask}

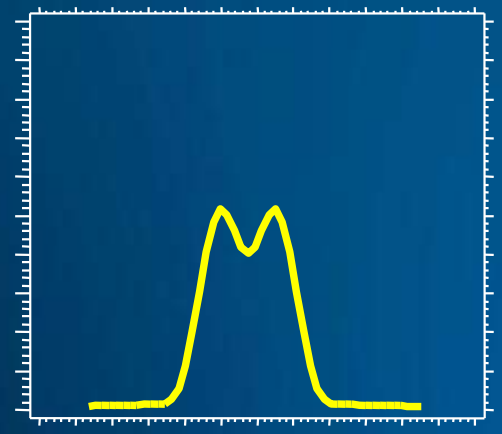

Conventional

Mask Structure

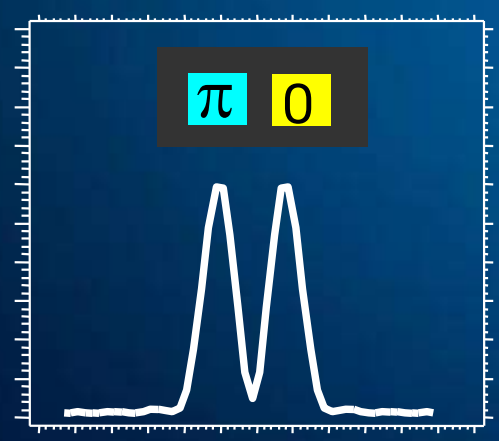

Alternate Phase Shift
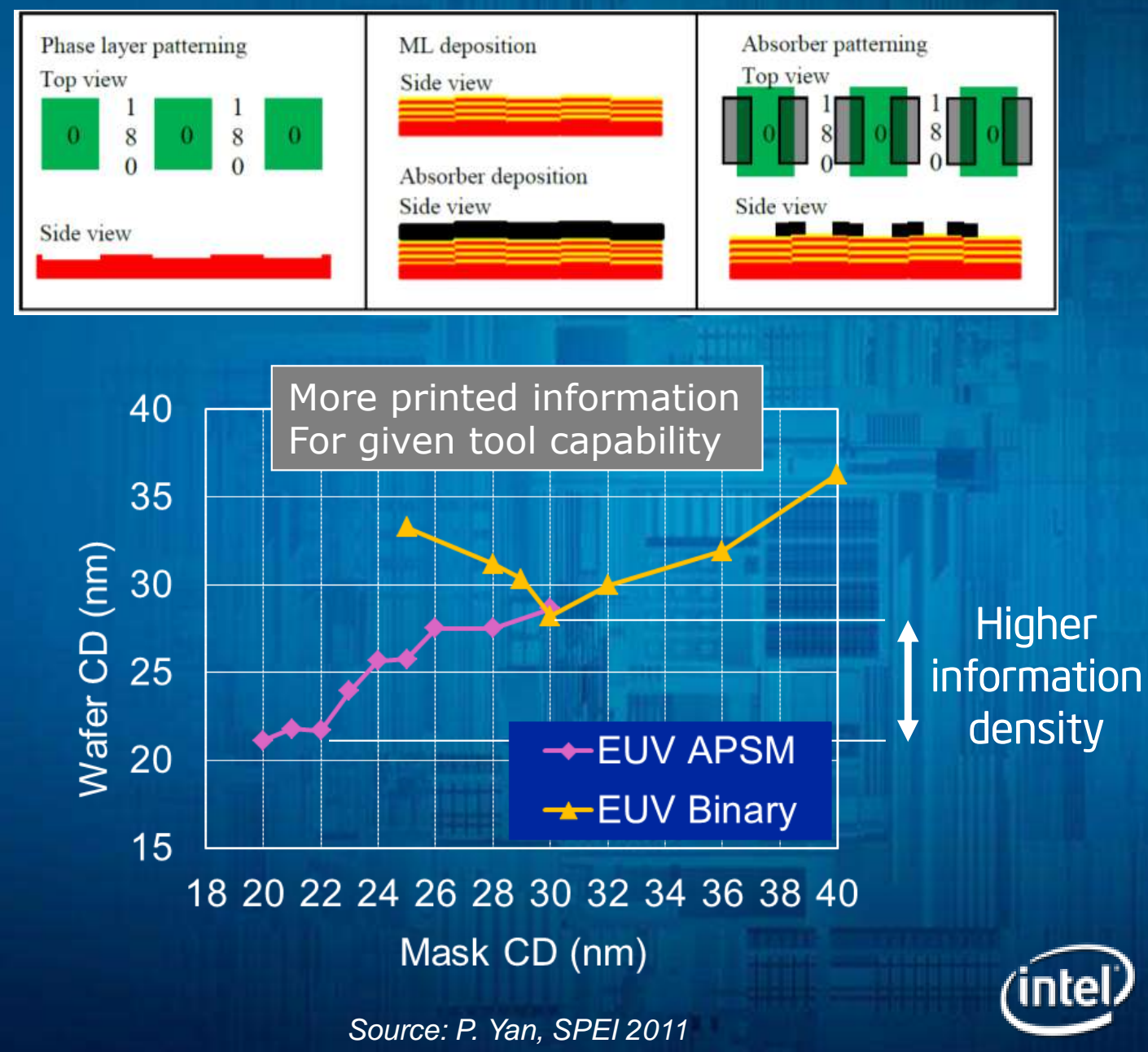


\section{Are there fundamental physical limits?}

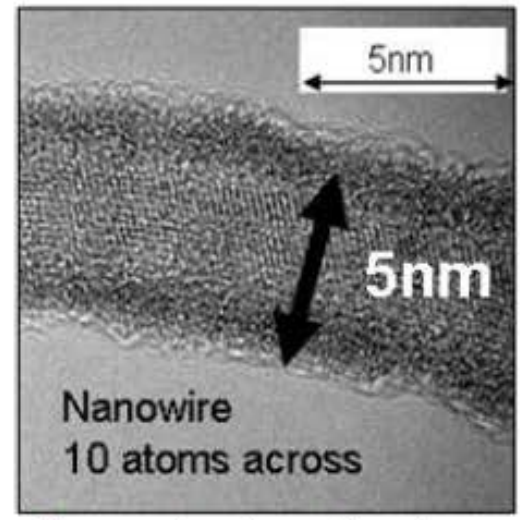

$5 \mathrm{~nm}$ device feature

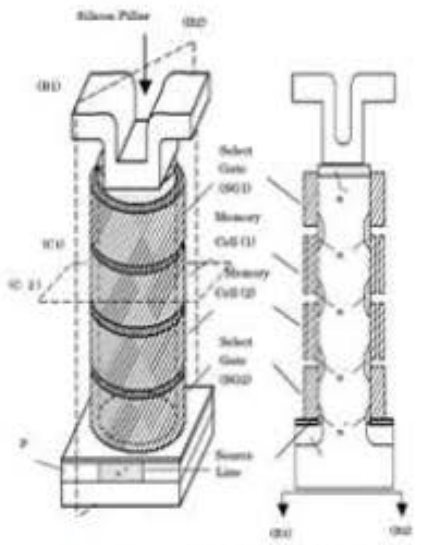

Source: Endoh,TED 2003

Vertical devices

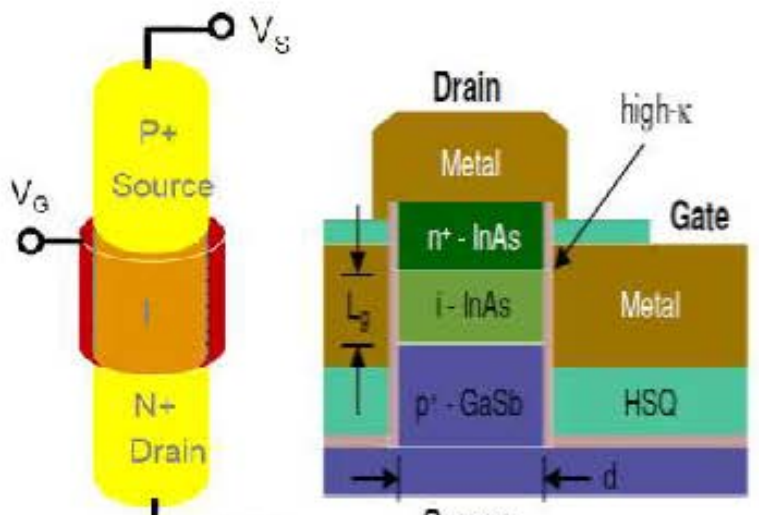

Source

III-V Vertical Tunnel FETs

Vertical device structures and new materials

- 5nm device structures have been demonstrated in research labs

- New device architectures are under investigation

Our ability to control is more a limitation than the physics

Control implies we can measure and co-optimize 


\section{Managing Material Properties at Nanometer Scale}

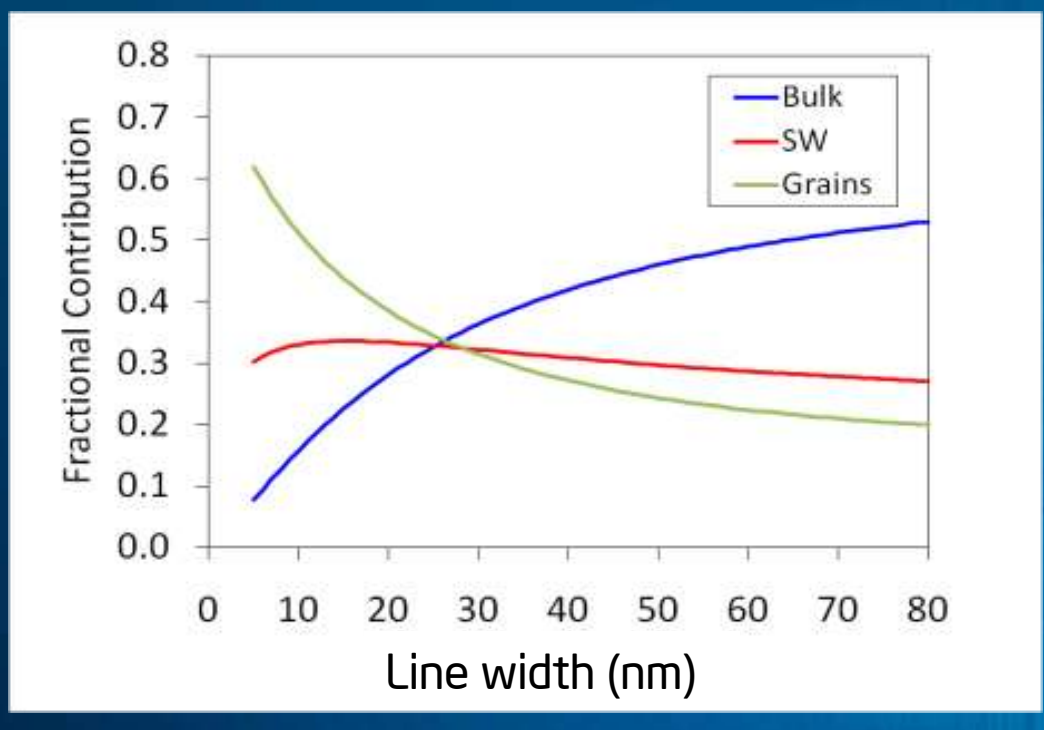

\section{Grain scattering dominates
Need sub-nm material engineering \\ Grain scattering dominates
Need sub-nm material engineering}
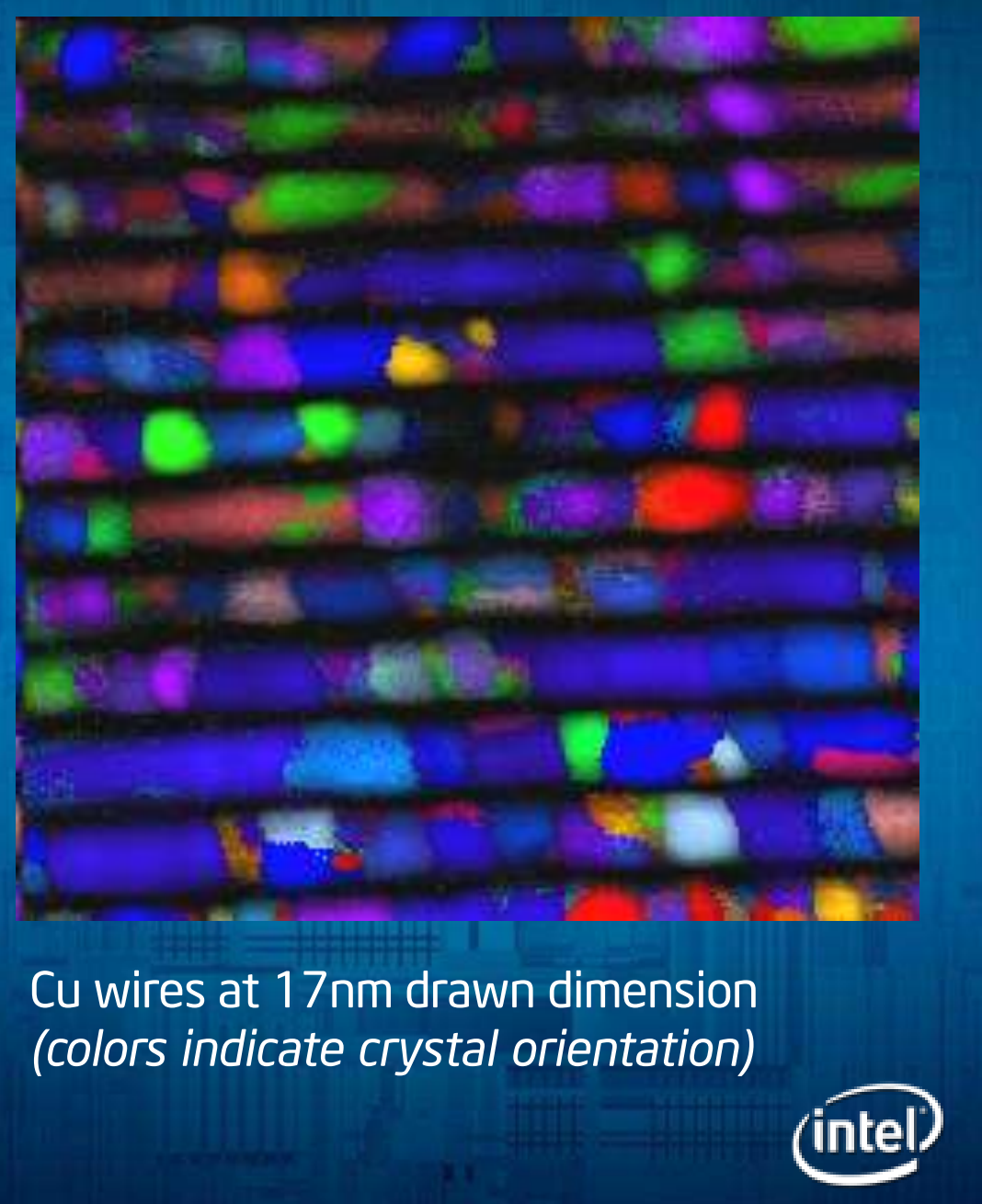


\section{Another Sub-nm Example}

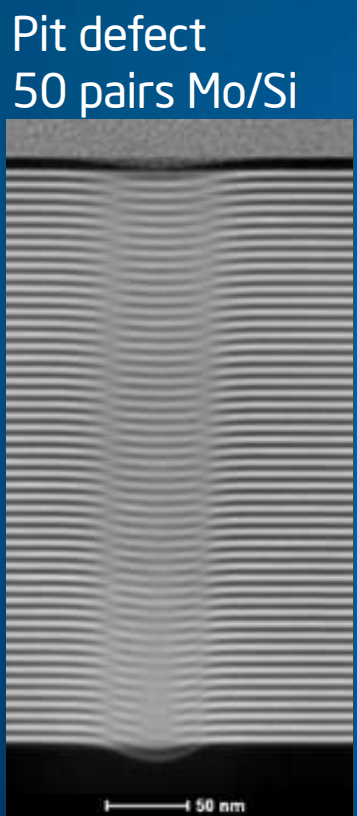

Bump defect

40 pairs $\mathrm{Mo} / \mathrm{Si}$

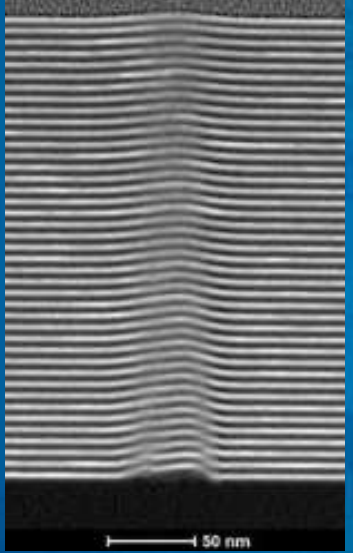

TEM of 50 -pair ML covered $11 \mathrm{~nm}$ etched step

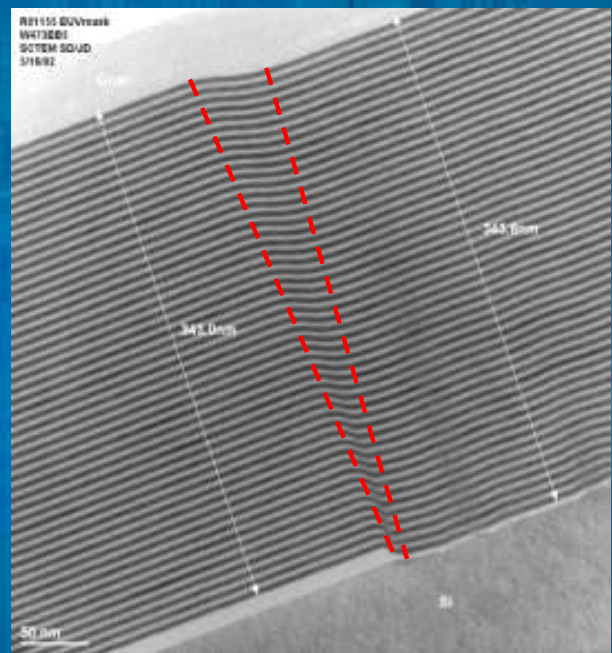

Source: Courtesy of SEMATECH and P. Yan, SPEI 2011 


\section{How Small Can We Fabricate and Control?}

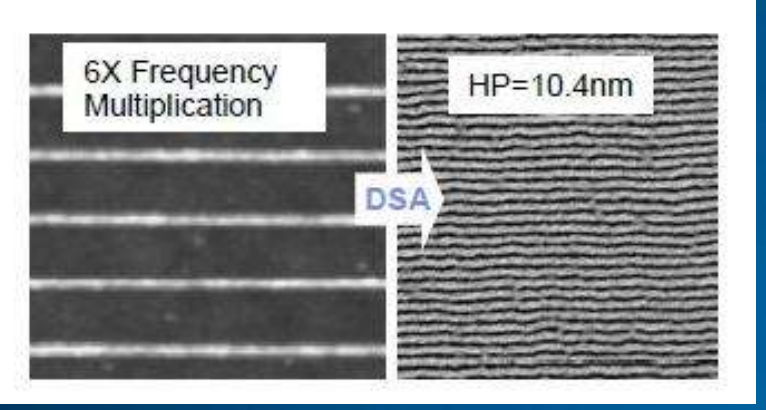

"Self-Assembling Materials for Lithographic Patterning" Bill Hinsberg et al, IBM.SPIE 2010

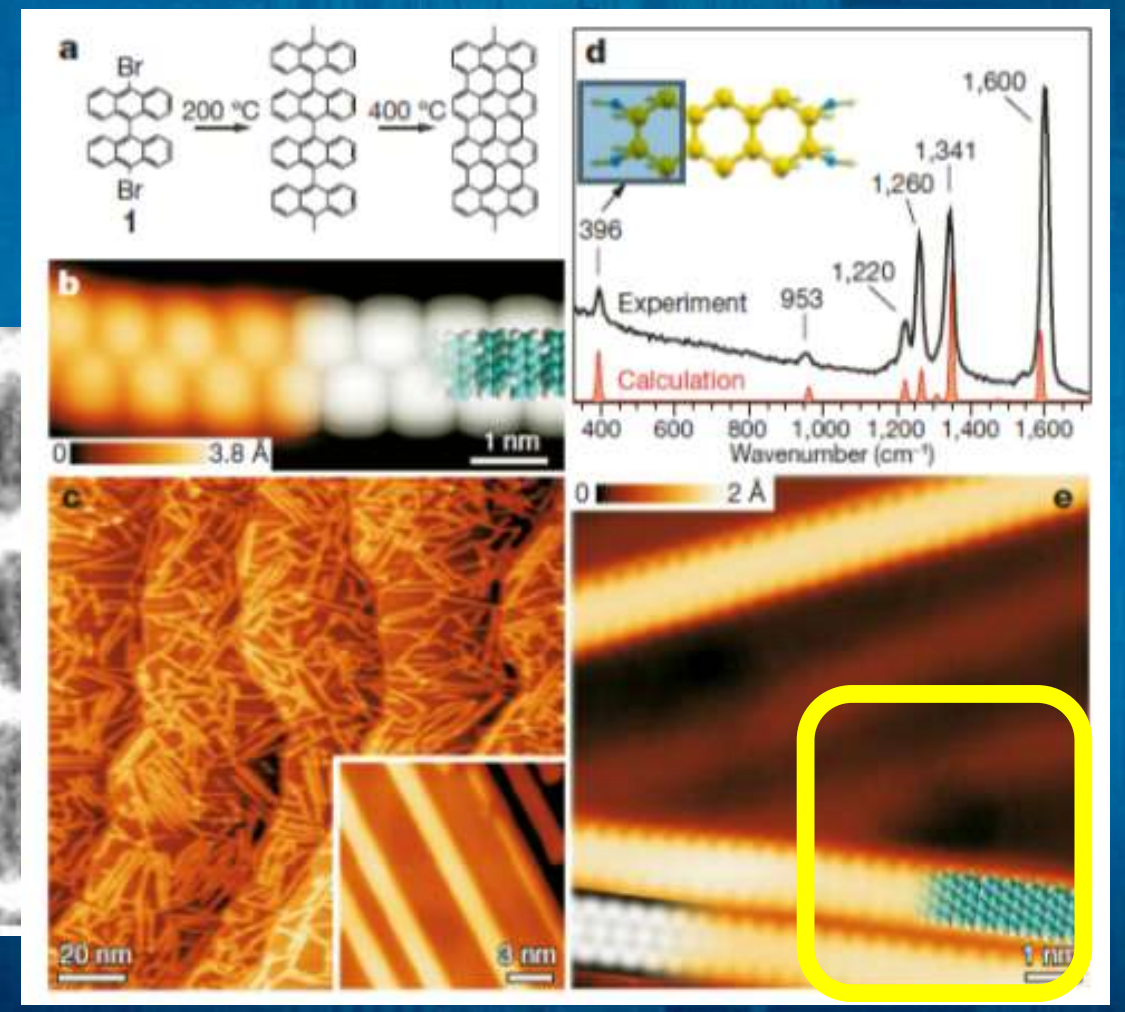

IBM, Park et al, Nanotech 192008

Cai et al, Nature July 2010

(intel) 


\section{Control Requires Co-Optimization}

\section{Production Share}

\section{Has dramatically shifted into captive production}
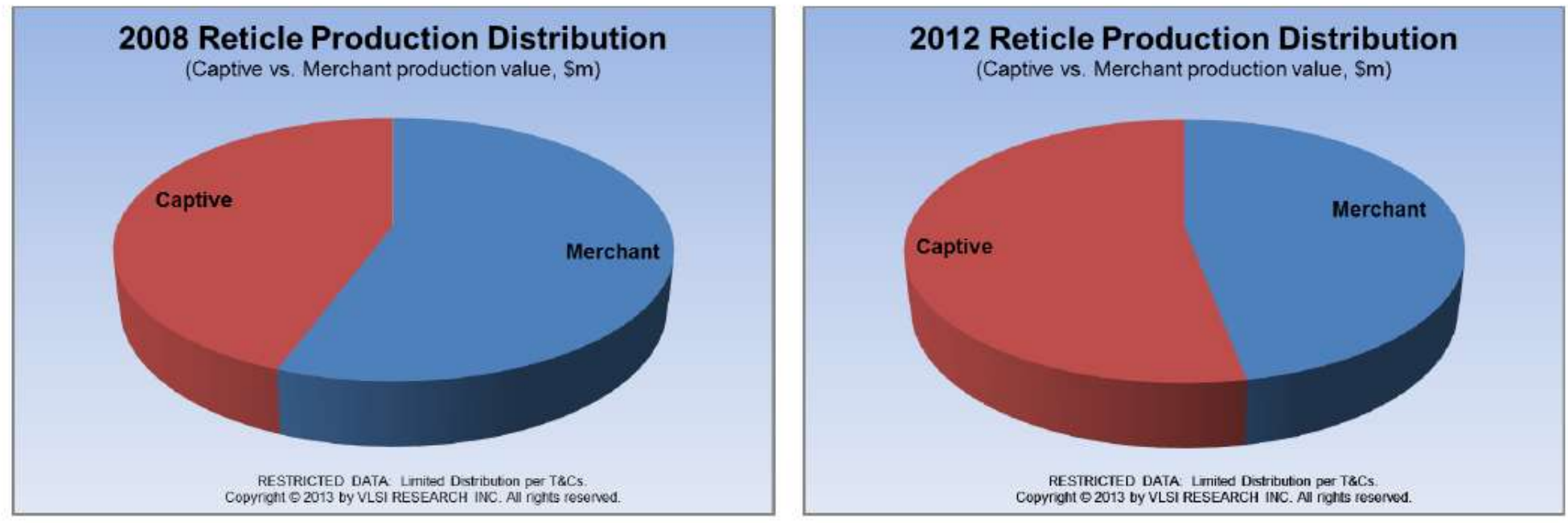

Source: Courtesy of VLSI Research 2013 


\section{Inflection Points}

\section{Granularity \\ Size limited by Electrical behavior Voltage scaling limited by Mobility Interconnects limit performance}

"The only way of discovering the limits of the possible
is to venture a little way past them into the impossible"

- Arthur C. Clarke 1962 


\section{Alternative paths}

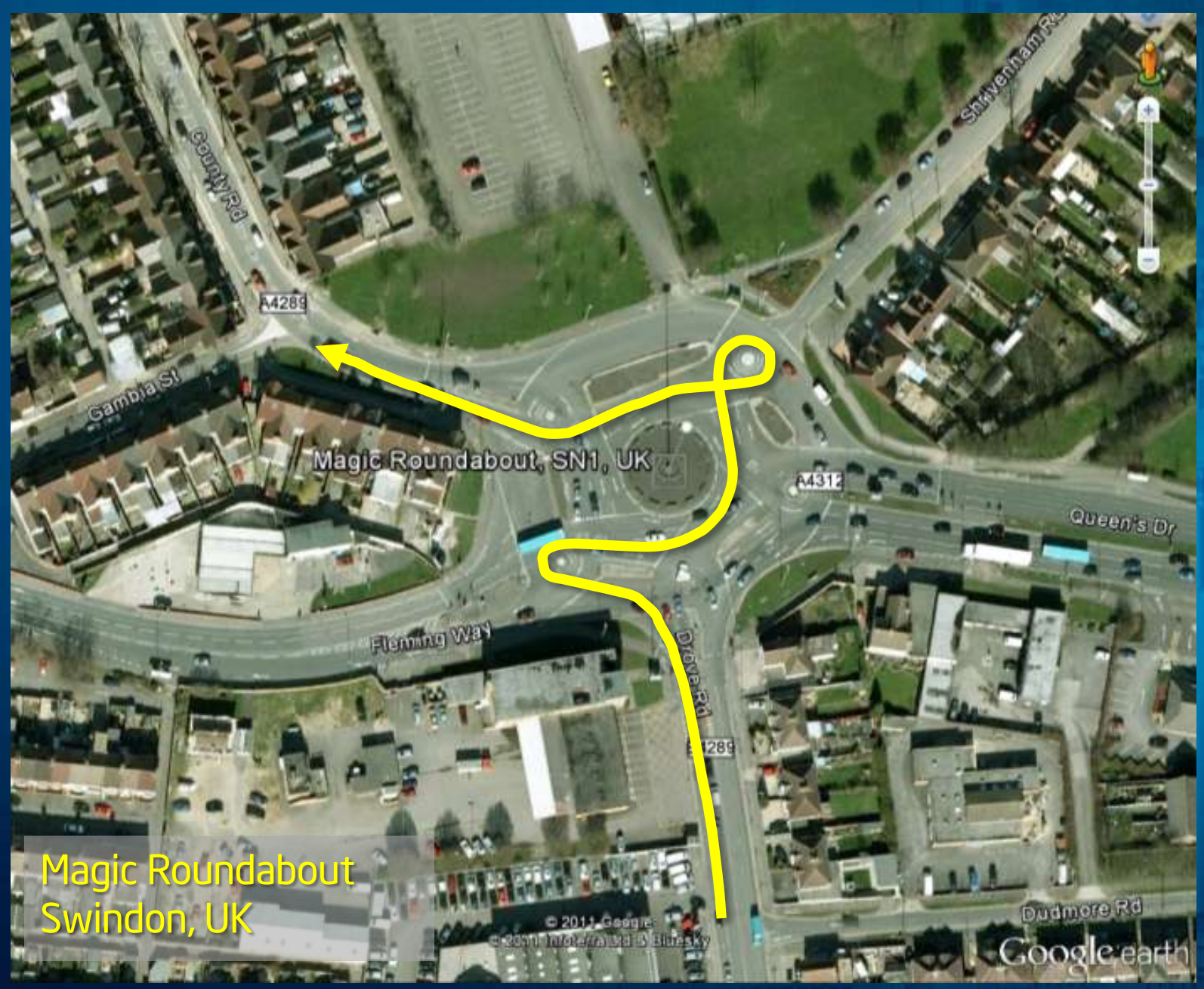




\section{Heterogeneous System Integration}
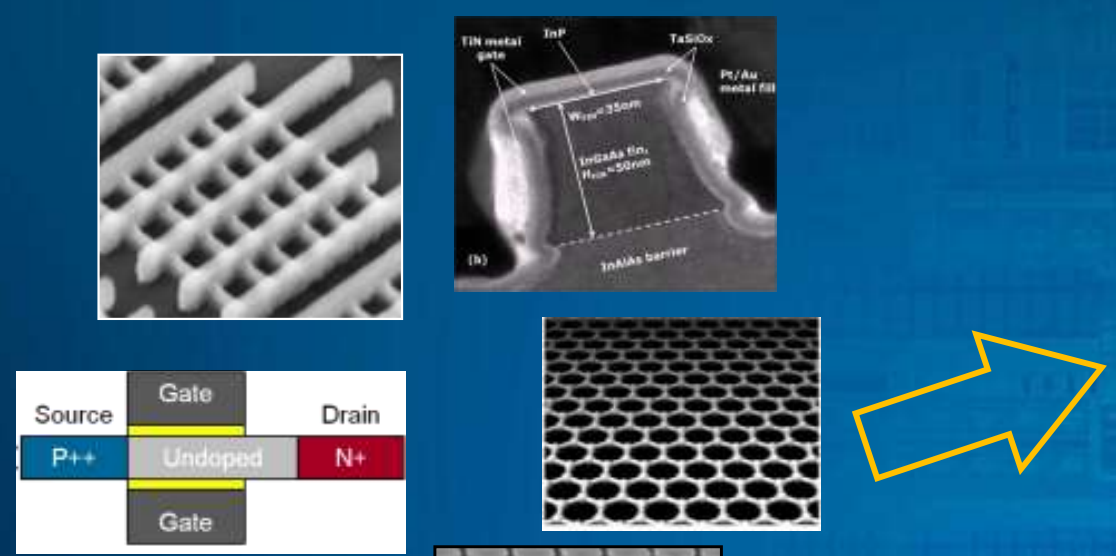

2-D Integration (SoC)
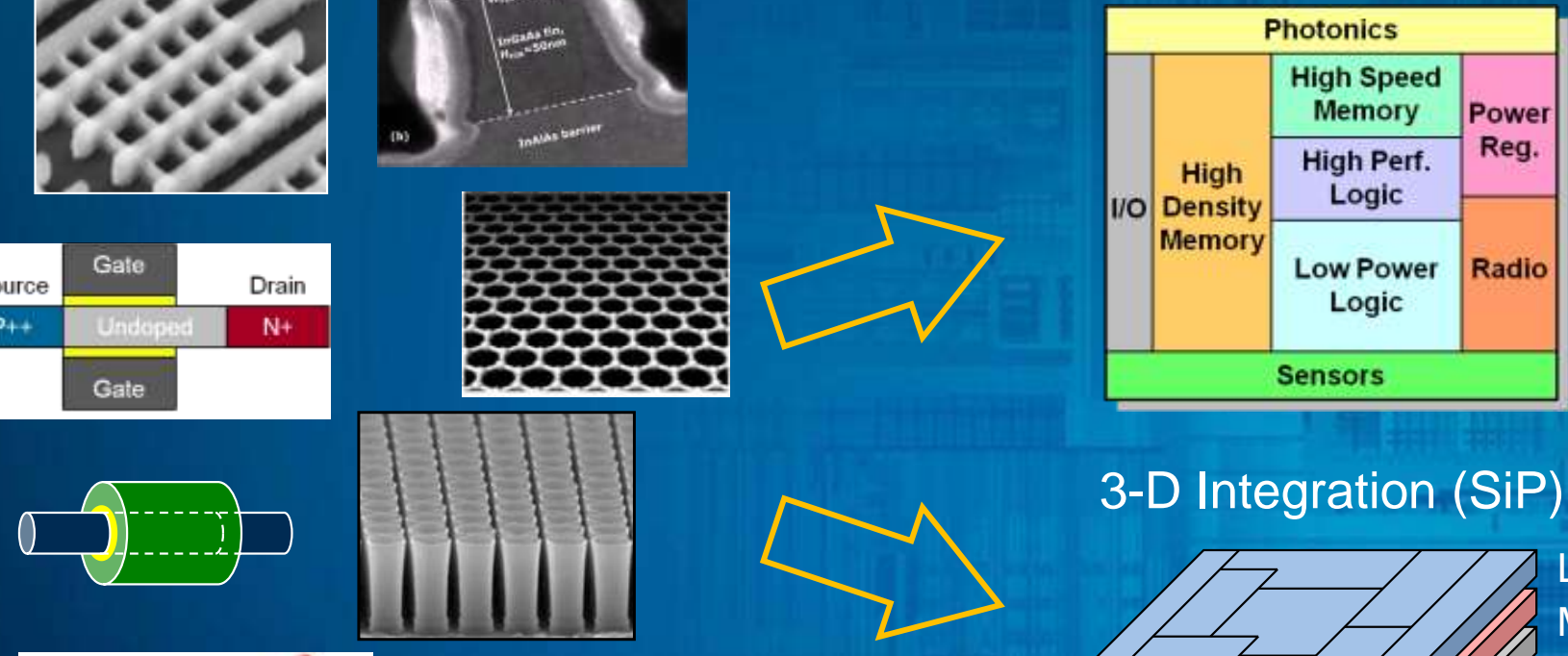

\section{3-D Integration (SiP)}

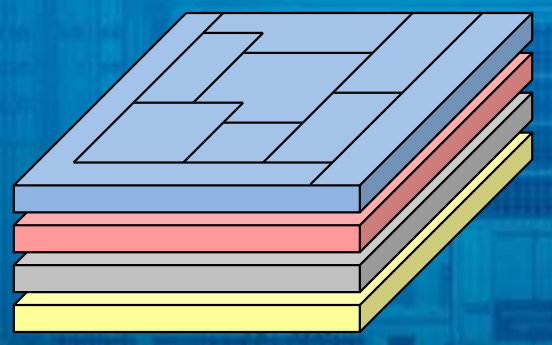

Logic Memory Power Reg. Radio Sensors Photonics

Future systems will integrate a much wider variety of materials and device structures

Source: IEDM 2011: The Evolution of Scaling from the Homogeneous Era to the Heterogeneous Era, M. Bohr 


\section{Layer Stack Density Benefit: 30-50\%}

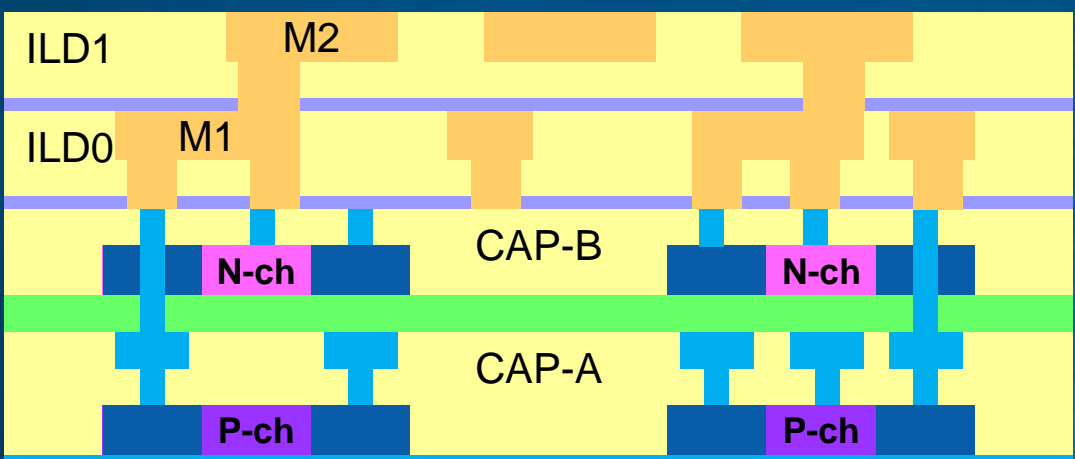

\section{Stacked Latch}

\$
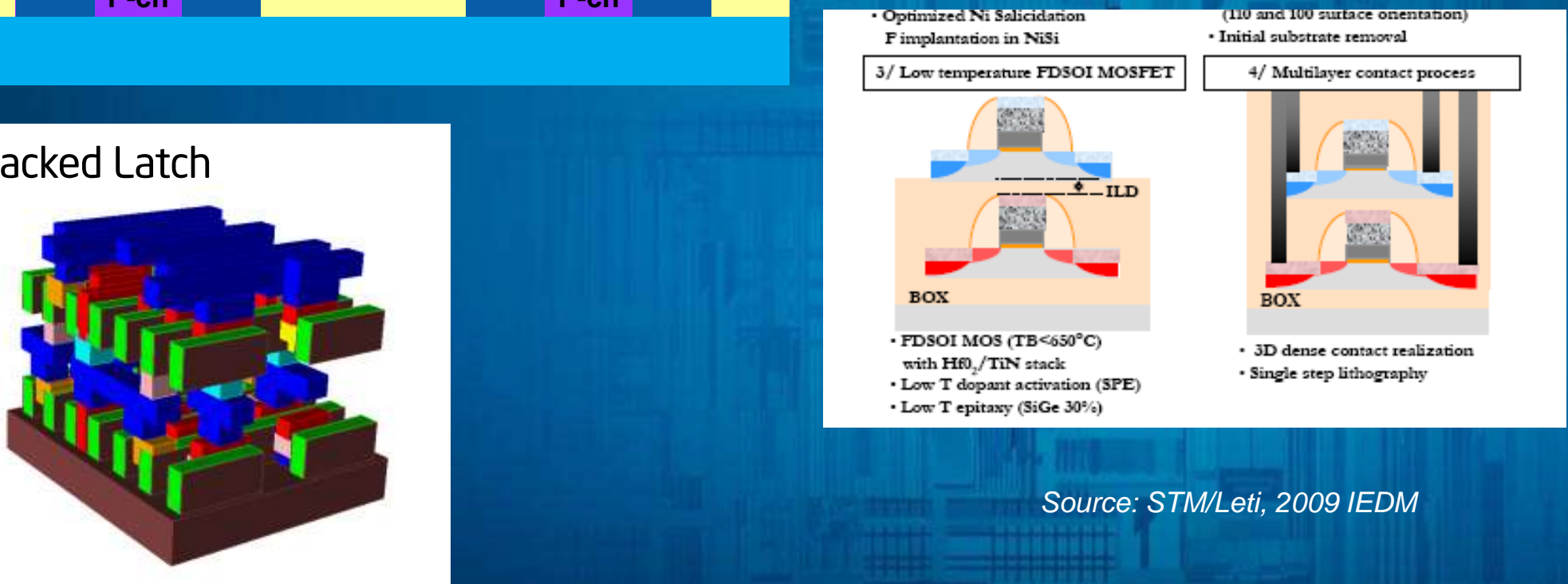

Source: STM/Leti, 2009 IEDM

\section{Widespread use requires new design methods ... and some new metrology}




\section{Beyond CMOS Devices - Noncharge}

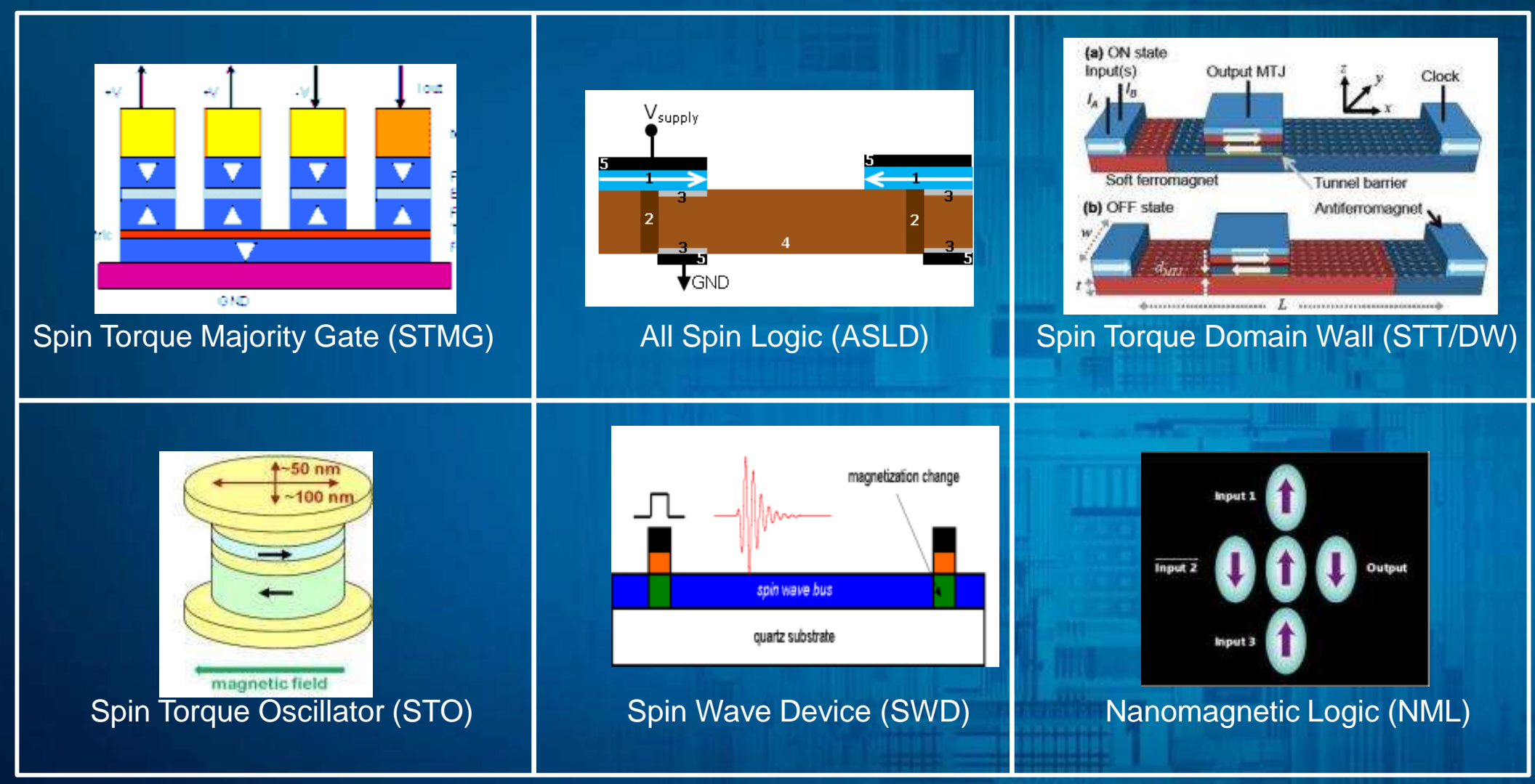

Source: D. Nikonov and I. Young, 2012 IEDM 


\section{Exploring Other Ways to Compute}

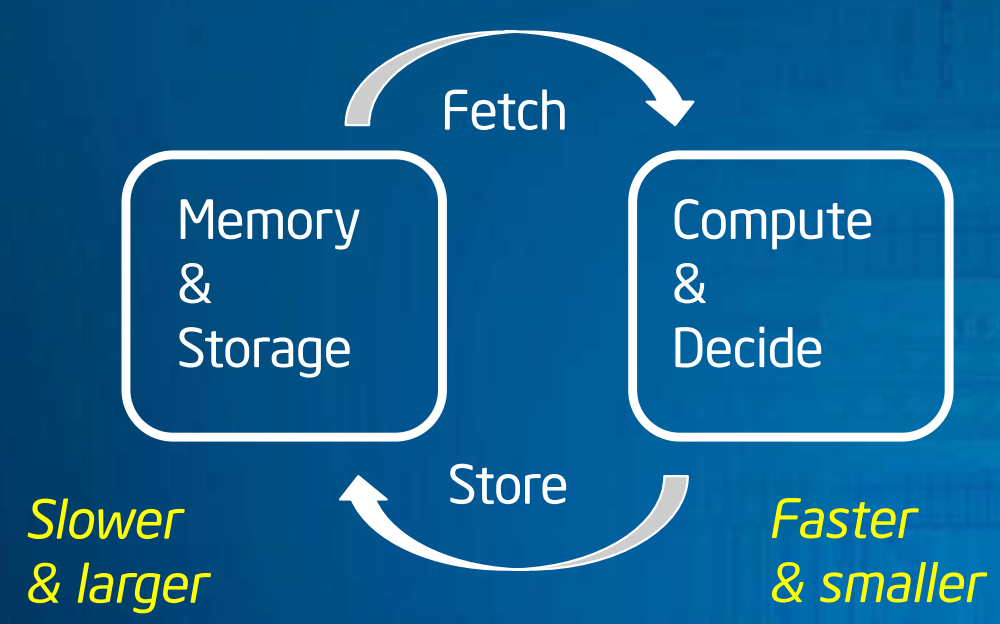

"Von Neumann"

Bottleneck = memory/storage

Transport limited devices make it worse

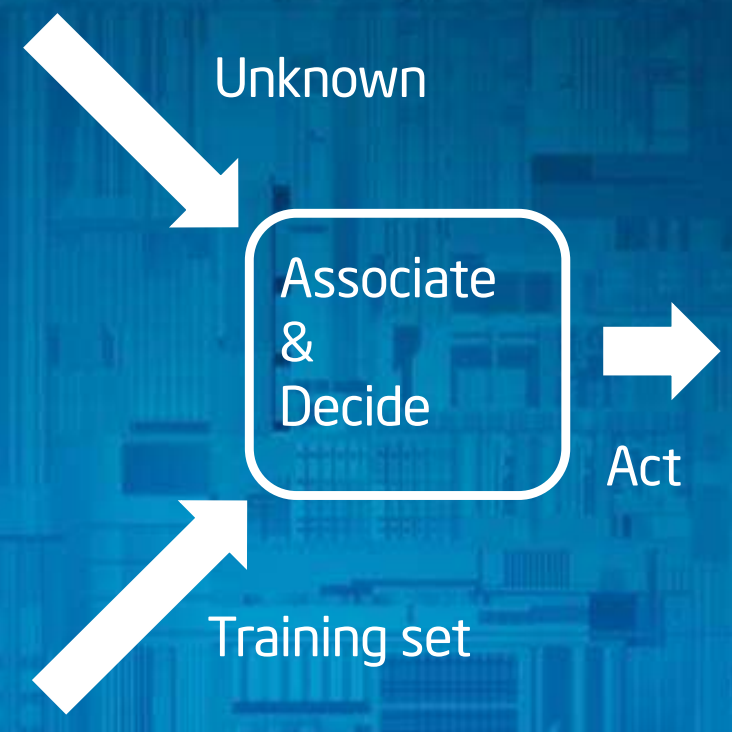

Bottleneck = training Potentially favorable for novel devices 


\section{The Future of Mask Fabrication?}

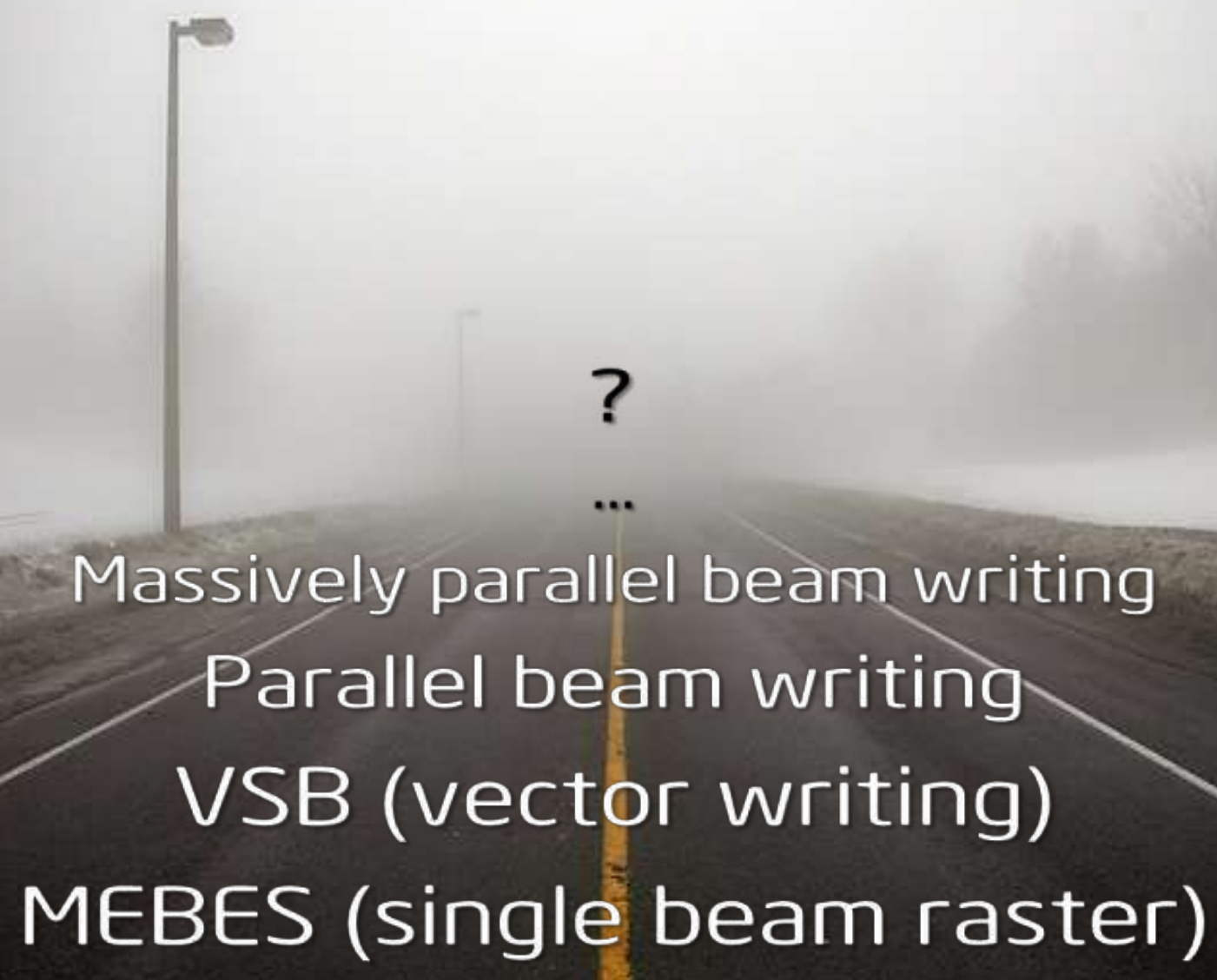




\section{Key Messages}

- Complexity sells ... and thus complexity is your friend

- Novel materials in complex 3D structures are here now and will be increasingly prevalent in the future

- Today we have even more choices than we have had in the past - this is both good and bad

- The future remains bright and masks remain an integral part of our future success 


\section{Thank You}

Proc. of SPIE Vol. $8880888002-29$

Downloaded From: https://www.spiedigitallibrary.org/conference-proceedings-of-spie on 26 Apr 2023 Terms of Use: https://www.spiedigitallibrary.org/terms-of-use 


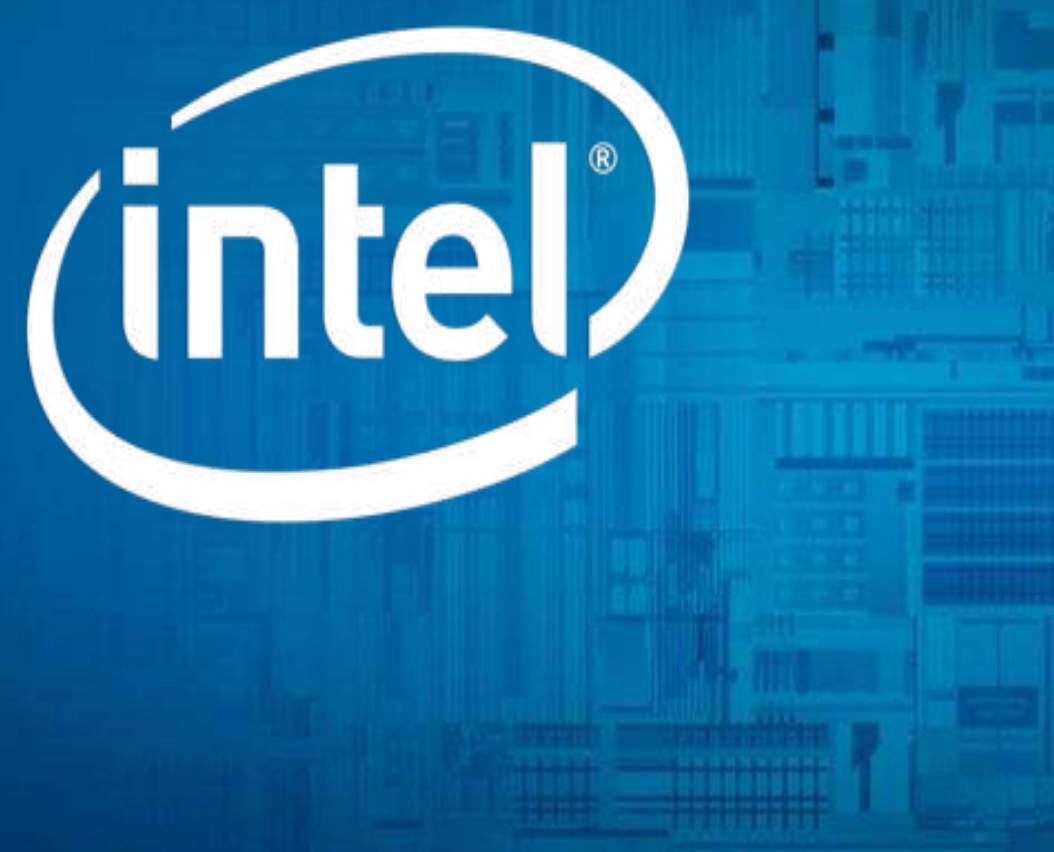

Proc. of SPIE Vol. $8880888002-30$

Downloaded From: https://www.spiedigitallibrary.org/conference-proceedings-of-spie on 26 Apr 2023 Terms of Use: https://www.spiedigitallibrary.org/terms-of-use 


\section{Risk Factors}

The above statements and any others in this document that refer to plans and expectations for the first quarter, the year and the future are forward-looking statements that involve a number of risks and uncertainties. Words such as "anticipates," "expects," "intends," "plans," "believes," "seeks," "estimates," "may," "will," "should" and their variations identify forward-looking statements. Statements that refer to or are based on projections, uncertain events or assumptions also identify forward-looking statements. Many factors could affect Intel's actual results, and variances from Intel's current expectations regarding such factors could cause actual results to differ materially from those expressed in these forward-looking statements. Intel presently considers the following to be the important factors that could cause actual results to differ materially from the company's expectations. Demand could be different from Intel's expectations due to factors including changes in business and economic conditions, including supply constraints and other disruptions affecting customers; customer acceptance of Intel's and competitors' products; changes in customer order patterns including order cancellations; and changes in the level of inventory at customers. Uncertainty in global economic and financial conditions poses a risk that consumers and businesses may defer purchases in response to negative financial events, which could negatively affect product demand and other related matters. Intel operates in intensely competitive industries that are characterized by a high percentage of costs that are fixed or difficult to reduce in the short term and product demand that is highly variable and difficult to forecast. Revenue and the gross margin percentage are affected by the timing of Intel product introductions and the demand for and market acceptance of Intel's products; actions taken by Intel's competitors, including product offerings and introductions, marketing programs and pricing pressures and Intel's response to such actions; and Intel's ability to respond quickly to technological developments and to incorporate new features into its products. Intel is in the process of transitioning to its next generation of products on 22nm process technology, and there could be execution and timing issues associated with these changes, including products defects and errata and lower than anticipated manufacturing yields. The gross margin percentage could vary significantly from expectations based on capacity utilization; variations in inventory valuation, including variations related to the timing of qualifying products for sale; changes in revenue levels; product mix and pricing; the timing and execution of the manufacturing ramp and associated costs; start-up costs; excess or obsolete inventory; changes in unit costs; defects or disruptions in the supply of materials or resources; product manufacturing quality/yields; and impairments of long-lived assets, including manufacturing, assembly/test and intangible assets. The majority of Intel's non-marketable equity investment portfolio balance is concentrated in companies in the flash memory market segment, and declines in this market segment or changes in management's plans with respect to Intel's investments in this market segment could result in significant impairment charges, impacting restructuring charges as well as gains/losses on equity investments and interest and other. Intel's results could be affected by adverse economic, social, political and physical/infrastructure conditions in countries where Intel, its customers or its suppliers operate, including military conflict and other security risks, natural disasters, infrastructure disruptions, health concerns and fluctuations in currency exchange rates. Expenses, particularly certain marketing and compensation expenses, as well as restructuring and asset impairment charges, vary depending on the level of demand for Intel's products and the level of revenue and profits. Intel's results could be affected by the timing of closing of acquisitions and divestitures. Intel's results could be affected by adverse effects associated with product defects and errata (deviations from published specifications), and by litigation or regulatory matters involving intellectual property, stockholder, consumer, antitrust and other issues, such as the litigation and regulatory matters described in Intel's SEC reports. An unfavorable ruling could include monetary damages or an injunction prohibiting us from manufacturing or selling one or more products, precluding particular business practices, impacting Intel's ability to design its products, or requiring other remedies such as compulsory licensing of intellectual property. A detailed discussion of these and other factors that could affect Intel's results is included in Intel's SEC filings, including the annual report on Form 10-K for the fiscal year ended December 31, 2012. 